\title{
Mahatma Gandhi Institute of Medical Sciences Sewagram: Medical Education and Health Care with a Difference
}

\author{
Shakuntala Chhabra, Naina Kumar
}

\section{Background}

Mahatma Gandhi Institute of Medical Sciences (MGIMS), India's first rural medical institute, nestled on Gandhi's land, Sewagram, Maharashtra, India, was founded by Dr. Sushila Nayar in 1969, as a Gandhi Centenary Project. Its Kasturba Hospital has distinction of being the only hospital which was started by Gandhi himself, as a two-bedded dispensary in 1938, converted into a 15 bedded hospital for women and children in 1944. It is now a 980 bedded hospital, committed to the pursuit of professional excellence by evolving an integrated pattern of medical education and health care. It seeks to provide accessible, affordable, excellent care to the masses and teach students with community bias.

With its first batch of 60 medical students ( 5 added later), MGIMS is independent India's first attempt to give new direction to rural health. From the 2012-13 academic session, undergraduate seats have been increased to 100 , half from Maharashtra and the rest from other States of India, giving a real example of national integration.

There is reservation for rural students, in addition to reservations as per the country's norms. It boasts of having groomed more than 2300 doctors, scattered around globe.

\section{Medical Education in MGIMS}

Like any medical colleges, the institute provides medical education, health services,

\footnotetext{
${ }^{1}$ Department of Obstetrics Gynaecology

Mahatma Gandhi Institute of Medical Sciences

Sevagram, Wardha - 442102

Maharashtra, India.

Corresponding Author:

Dr. Shakuntala Chhabra

Director, Professor

Obstetrics Gynecology

Mahatma Gandhi Institute of Medical

Sciences Sevagram, Wardha - 442102

Maharashtra, India.

+91-7152-284341 to 55; (O) 321,307; (R) 221

Email:chhabras@rediffmail.com
}

community services, does research, has academics, but is still different in many ways. It has its own entrance examination with paper on "Gandhian Thoughts", Gandhiji's life, his vision, associates' vision, principles of Ahimsa (non-violence) Satya (truth) and love. Passing is essential and marks carry the necessary weight in merit for admission. Not only the students but their whole families become acquainted with gandhian ways of life as they help their wards in preparation for examinations.

Social accountability can be defined as "An obligation to direct education, research and service activities towards addressing priority health concerns of community, region, and / or nation they have a mandate to serve" (Boelen, 2000; 2002). Not many medical colleges in South East Asia or around globe are involved in community services as part of social accountability. Medical collages that are involved in community services as part of social accountability are rare in South-East Asia and even around the globe. Makerere College of Health Sciences (MakCHS), Uganda (Galukande, 2012), Northern Ontario School of Medicine (NOSM), Canada (Health Canada, 2001), Southern Illinois University School of Medicine, USA, Hull York Medical School, UK are some such leading ones. By accepting a vital societal role, medical colleges accept that they have a responsibility to provide medical education that produces competent, compassionate, confident doctors who are ready to meet society's present and future needs.

While medical colleges aim to promote health through three basic functions: education, research and service (Lewkonia, 2002) involvement of stakeholders in the health sector at community, regional and national levels (Rourke, 2013) is essential to produce doctors who understand their role in the context of community and society and are prepared to provide needs based care (Tamblyn,1999; Health Canada, 2008). Services provided by a medical collage need to include curative, preventive, rehabilitative, 
and promotive aspects considering health concerns of the community being served.

In India true examples of such colleges seem to be the Mahatma Gandhi Institute of Medical Sciences, Sewagram and the Christian Medical College, Vellore. These medical colleges conduct community services while imparting community based medical education. MGIMS is different in many ways as community services is the foundation stone of this institute. Soon after admission to the MBBS course, there is an Orientation Camp where students live in the Gandhi Ashram for 15 days and are oriented to Gandhian ideology in real life. Drawn from different geographical and cultural backgrounds of the country, this camp helps them get acquainted with each other, respect each other's religion, culture, learn simple ways of disciplined life, take care of their own needs, and develop respect for labor. However, theory classes on medical subjects are started due to time restrictions in the first year schedule. By the end of the first semester, a social service camp is conducted in which, students live in adapted villages in consensus with villagers where families are allocated to them with whom they remain attached for the whole duration of the undergraduate course. They live in the village for 15 days; try to understand social health related problems of villagers and impart health education. The whole village gets screened with the help of specialists who visit village to run clinics. Students are responsible for the health of families allotted to them. They ensure that the illnesses are examined and treated and also that families participate in screening programs for malaria, filariasis and worm infestation. Students develop a bond with villagers and the experience leads to compassion and a sense of commitment towards serving rural communities. During the final year of MBBS, students participate in a Reorientation of Medical Education (ROME) camp at the Rural Health Training Centre for 15 days where they observe clinical demonstrations of the association of social and environmental factors in health and disease. Students also develop an understanding of disease burden, treatment seeking behavior, and health infrastructure. They do relevant mini-projects in groups, to be able to help villagers. This programme was started at a national level as far back as 1977, but is almost defunctional similar to most other medical colleges. During internship Medical Council of India norms are followed, yet focus is given on learning rural community services.
The Institute expects all its graduates to serve for 2 years in rural regions, a mandatory criterion when applying for post-graduation in this Institution, but not a guarantee for postgraduate registration. This helps rural communities as doctors are aware of ground realities before doing post-graduate studies. 96 non-governmental organizations (NGOs) have joined hands with the Institute to fulfill this dream. In this manner MGIMS strives to produce doctors of high clinical competence, professional attitudes ethical values with community oriented education.

\section{The Unique Code of Conduct}

Students, staff, employees of the Institute adhere to a code of conduct, by wearing handwoven khadi, participate in shramdan (perform voluntary tasks in the campus, to keep it clean) and in an all-religion prayer every Friday evening. The Institute follows a strict vegetarianism policy. Alcohol and tobacco consumption are strictly prohibited.

\section{Departments and Disciplines}

The Institute offers degrees, diplomas in 20 disciplines recognized by Medical Council of India and PhDs in 8 Departments recognized by the Maharashtra University of Health Sciences, Nashik (MUHS), to which it is affiliated through its 24 teaching and research departments. In spite of its strong social focus, the institute is not lagging behind in academic developments, students' performances, conferences, Continued Medical Education (CME) programs and sports.

\section{Research}

Focus of the Institute is on needs based quality research with a large number of funded, non-funded projects in each department receiving support from national and international organizations such as ICMR, Department of Biotechnology, WHO, UNICEF, USAID, Fogarty AIDS Research and Training Program, USA and many others. Each year many publications provide evidence of excellence in research. The institution has many In- House Publications such as the Journal of MGIMS, News Bulletin, Sevamed, Bioinformatics Centre and JBTDRC Sushruta, Hamari Chitthi Apke Naam.

\section{Health Care}

The Kasturba Hospital, offers services of Ayurveda and Naturopathy in addition to regular outpatient, inpatient services in all 
specialties with day to day emphasis on clinical acumen and cost effective care. Almost two-thirds of patients who utilize services are rural. Though it is a rural institute, it does not lack modern health care amenities and provides excellent health services at affordable costs.

There has been a gradual increase in the number of patients seeking treatment from the hospital. Between April 2012 and March 2013, of 709,200 patients attending hospital's different outpatient departments 44,903 were admitted for various ailments. The hospital has state-of- art intensive care units and the only Blood Component Unit in the District which provides components to patients of Kasturba Hospital, and adjoining hospitals. A wellequipped hemodialysis unit is in place. The institute has a Linear accelerator to provide the best of cancer therapy and clinical research laboratories have in-house facilities to conduct a battery of diagnostic tests. The hospital has an advanced Hospital Information System.

\section{Community Services}

The Institute works on the concept of social accountability. Under public and private partnership, three primary health centers have been attached to the institution by the government, a model of decentralized healthcare delivery at village level through self-help groups, farmers' development schemes and adolescents' education for overall development of communities and women's empowerment. The Institute also conducts various screening camps, not only in villages of 8 blocks of the Wardha District, but in adjoining districts for the detection and treatment of endemic diseases. The Ophthalmology team conducts regular screening camps for detection and treatment of cataract. Similarly, nurse midwives from Obstetrics (OBGY) department conducts regular visits to adopted villages, provide antenatal care with intra natal, and postnatal advocacy to reduce maternal and neonatal morbidity and mortality. Every 5 years, screening camps are conducted for gynaecological disorders, precancerous conditions and cervical cancer. A family life education program for adolescent girls is also provided.

To deal with stigma of unwed mothers and unwanted babies, the OBGY runs the "Sewagram project" for unwed mothers who report with advanced unwanted pregnancies, when abortion is not possible as per country's abortion law. Unwed mothers are provided social, medical and financial help for safe birth. There is a legal system of custody, where adoption of babies of such mothers who do not want to take home their babies takes place under KHS which runs MGIMS, Sewagram. In this way the institution is helping unwed mothers and their babies by securing their future and helping needy parents by providing them most valuable gift of life under all legal norms.

Institute also runs an integrative health care, research project known as Arogyadham for promotion of positive health. It has naturopathy / yoga treatment -cumpropagation centre supported by the Central Council for Research in Yoga and Naturopathy, Department of AYUSH. It takes care of preventive and curative aspects of life style illnesses such as hypertension, back pain, bronchial asthma, and diabetes.

A new feature added is Mahatma Gandhi Adiwasi Dawakhana, Mata Va Shishu Rugnalaya in Utawali, Dharni, Amravati, Maharashtra, since $1^{\text {st }}$ January 2012 from a generous donation by Brihad Bhartiya Samaj, Mumbai. Since then the hospital has been serving people of Melghat, a hilly, forestry regionwith difficult access transport problems, infamous for high perinatal, infant, child, and maternal mortality rates.

\section{Cost Effective Services and Health Consciousness}

The institution has its own annual Health Insurance Schemes to create health consciousness in community, provide services at low cost, avoid charity, and provide health care at doorstep to needy rural people.

1. General Scheme: A person can insure his/her family (up to 5 members) by paying Rs 350 year, in return gets a $50 \%$ subsidy in outpatient and inpatient services with $10 \%$ subsidy on CT and MRI.

2. Institutional Schemes: Head of any industry or institution can insure his/her employees and their families by paying a premium of Rs 70 per head, in return for the same benefits as that of the general scheme.

3. Jawar Scheme: Rural beneficiaries pay according to their capacity, even in kind, such as jawar (sorghum), in return get free treatment for emergencies, delivery of primigravida including perinatal care, unforeseen illness, free meals and 50\% 
subsidy on other illnesses and outpatient services.

4. Village Scheme: Family pays Rs $35 /$ member/ year, in return receives thesame benefits as that of the general scheme, only prerequisite is that $\geq 75 \%$ families of a particular village need to be insured.

5. Small Saving groups Scheme: Similar to the village scheme, the only difference being that it is for registered Small Saving groups or Bachat Gat.

6. Inpatient Slip: One time use scheme for inpatient care only. Person has to pay Rs 140 per slip and in return gets same benefits as that of the general scheme but for one time.

\section{Awards and Recognition}

The National Rural Health Mission has lauded the 'positive contribution of MGIMS in health activities conducted in partnership with the Government of India.' In 2006, the Institute was awarded the Mahaveer Award for Excellence in the Sphere of Education, Medicine by the Honorable President of India. The Institution was honored with the National Award for Innovative Hospital Health care Management by the Bombay Management Association in 1990. MGIMS ranks at number 21 amongst top 25 best Medical Colleges of country according to Outlook India.com magazine 2012. The Institute has been accredited as grade $A$ by the NAAC in recognition of its academic, research and health care activities, and awarded the Global Safe Motherhood Award in 2001 by the White Ribbon Alliance for Safe Motherhood and the Global Council, USA in recognition of its Suraksha Aichi campaign in nearby villages. Other Awards include BC Roy awards, Best Teacher awards, and FIGO Awards.

The village name "Sewagram" means service with no returns and MGIMS Sewagram lives up to the name. Looking from a microscope at that time, perhaps Gandhi did see a tiny seed grow into the tree with flowers and fruits; an institution of this stature which serves the needy masses.

\section{Acknowledgement}

We thank the Presidents and Secretaries of the Kasturba Health Society, Sewagram and all the Deans and Medical Superintendents who have put their best over years to bring the institute to its present state.

\section{References}

Boelen, C. (2000) Challenges and opportunities for partnership in Health development, Geneva: WHO [Online] Available at: http://whqlibdoc. who.int/hg/2000/WHO_EIP_OSD_2000.9.pdf

Boelen, C. (2002) A new paradigm for medical schools a century after Flexner's report, Bulletin of the World Health Organization,80, 7, pp. 592593.

Galukande, M., Nakasujja, N.\&Sewankambo, N.K. (2012) Social accountability: a survey of perceptions and evidence of its expression at a Sub Saharan African university, BMC Medical Education, 12, 96.

Health Canada (2008) Social Accountability: A Vision for Canadian Medical Schools, Ottawa, Ontario: Health Canada, [Online] Available at: www.afmc.ca/pdf/pdf_sa_vision_canadian_medi cal_schools_en.pdf

Lewkonia, R. (2002)The Functional Relationships of Medical Schools and Health Services, Medical Education, 36, 3, pp. 289-295.

Outlook, MDRA, (2012, June 25.) Top Medical and Dental colleges, [Online] Available at: http://www.outlookindia.com/article.aspx?28130 0 .

Rourke, J. (2013) AM Last Page: Social Accountability of Medical Schools, Academic Medicine,88, 3, p. 430.

Tamblyn, R. (1999) Outcomes in Medical Education: What is the Standard and Outcomes of the Care Delivery by our Graduate, Practice, 4, 1, pp.925. 